The Free Internet Journal

for Organic Chemistry
Review

Arkivoc 2019, part ii, 144-162

\title{
Selenium-containing polymers: synthesis and applications
}

\author{
Elżbieta Wojaczyńska* and Andrzej Trochimczuk \\ Faculty of Chemistry, Wrocław University of Science and Technology, \\ Wybrzeże Wyspiańskiego 27, Wrocław 50 370, Poland \\ Email: elzbieta.wojaczynska@pwr.edu.pl
}

Dedicated to Professor Lorenzo Testaferri on the occasion of his $75^{\text {th }}$ birthday

Received 09-29-2019

Accepted 11-22-2019

Published on line 11-30-2019

\section{Abstract}

This mini-review focuses on selected connections between selenium and polymer chemistry: synthesis of Secontaining conjugated polymers, use of Se compounds as RAFT agents, and applications of immobilized Se derivatives in organic synthesis.

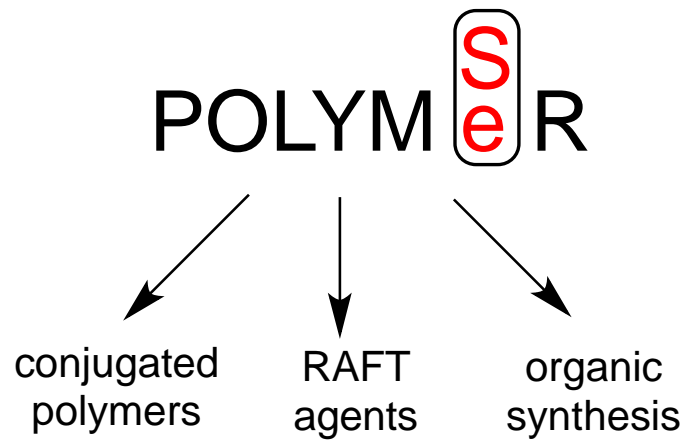

Keywords: Conjugated polymers, immobilization, polymerization, selenium 


\section{Table of Contents}

1. Introduction

2. Selenium-containing Conjugated Polymers

3. Selenium Compounds as RAFT Agents

4. Application of Selenium-containing Polymers in Chemical Synthesis

5. Conclusions

References

Authors' biographies

\section{Introduction}

Unique properties of selenium can be utilized to modify the properties of various materials. The use of its compounds in polymer science has gained an attention in the recent years, also due to their possible applications in the area of biomedical engineering. ${ }^{1}$ In the first part of this contribution, we focus on the recent achievements on the preparation of selenium-containing conjugated polymers. A review in this field appeared five years ago, ${ }^{2}$ and since that time new articles have been published. Another part is devoted to the use of Se compounds in controlled radical polymerization. The article concludes with examples of supported selenium compounds applied in organic synthesis.

\section{Selenium-containing Conjugated Polymers}

Selenium-containing polymers attracted the attention of researchers almost a hundred years ago. In the 1930s condensation reaction of 1,3-dibromopropane and sodium selenide was applied with the aim of preparation of cyclic selenohydrocarbons, but the main product of the reaction turned to be a short linear oligomer $\left(\mathrm{C}_{3} \mathrm{H}_{6} \mathrm{Se}\right)_{6 .}{ }^{3}$ Same authors reported identical reaction for the preparation of polyhexamethylene selenide. ${ }^{4}$ In later decades various groups reported on polymers with C-Se bond in the main chain; the simplest example is polyselenomethylene $-\left(\mathrm{CH}_{2} \mathrm{Se}\right)_{n}$ - obtained by Montillaro in the polymerization of 1,3,5-triselenane catalyzed with $\mathrm{BF}_{3} .^{5}$ Few years later, the same polymer was obtained by the condensation of dibromomethane with sodium selenide. ${ }^{6}$

Such polymers can be obtained with non-hydrogen substituents on carbon atoms but not with aromatic groups. ${ }^{7}$ However, the aromatic group can be a part of the main chain as the reaction of $\alpha, \alpha^{\prime}$-dichloro- $p$-xylene with sodium selenide yielded poly-seleno- $p$-xylene.

All the above-mentioned polymers were characterized and found to be solids with low melting points when many contiguous methylene groups were present in the main chain (for example, $36-37^{\circ} \mathrm{C}$ in the case of polyhexamethylene selenide), but much higher for polyselenomethylene $\left(210-220{ }^{\circ} \mathrm{C}\right)$, and $174-175{ }^{\circ} \mathrm{C}$ for poly-seleno- $p$-xylene. All of them were stable in air and all had electric resistivity reported to be ca. $10^{13-14} \Omega$ $\mathrm{cm}$.

Linear polymers with the $-\left(\mathrm{RSe}_{2}\right)$ - motif in the main chain were synthesized at almost the same time. A first example was poly-para-phenylene diselenide with $\mathrm{R}=p$-phenylene. ${ }^{8} \mathrm{~A}$ polymer with $\mathrm{R}=-\mathrm{CH}_{2}-$ was synthesized from hydrogen selenide and formaldehyde under anhydrous conditions. ${ }^{9}$ Poly-1,2-diselenoethylene was obtained by the oxidation of $\mathrm{HSeCH}_{2} \mathrm{CH}_{2} \mathrm{SeH}$ in a mixture of water and ethanol. ${ }^{3} \mathrm{~A}$ Grignard 
reagent was used to obtain polydiselenide with $\mathrm{R}=$ biphenyl. ${ }^{10}$ In this case the electric resistivity was slightly lower than for other Se containing polymers, being in the range $10^{11-12} \Omega \mathrm{cm}$.

An extension of the above work was reported in the 1990s, when Kobayashi and coworkers presented novel polymers based on 1,4-benzenediselenol and 1,4-divinylbenzene ${ }^{11}$ and conjugated polymers containing phenyl groups and Se in the main chain based on 1,4-benzenediselenol and 1,4-diethynylbenzene (Scheme 1). ${ }^{12}$

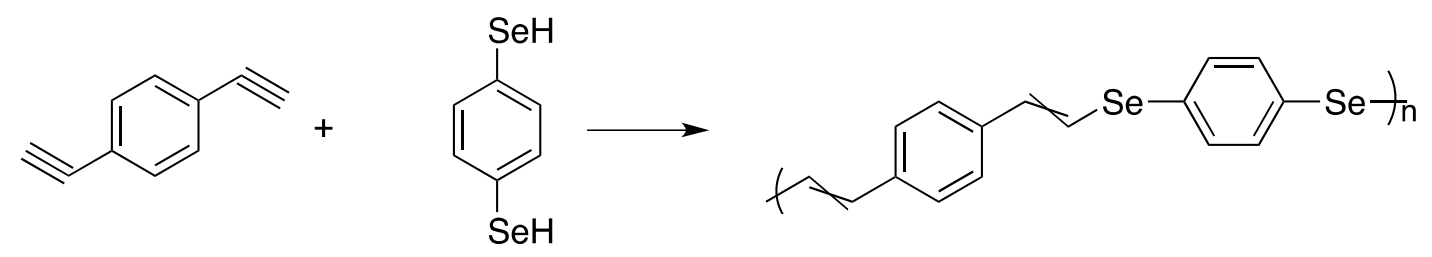

Scheme 1. Preparation of a conjugated polymer containing selenium. ${ }^{12}$

The mixture of monomers was polymerized using radical addition polymerization by UV irradiation of their solution in toluene. The yield of obtained polymer was in the range of 59 to $86 \%$, being higher when a higher proportion of 1,4-diethynylbenzene was used. However, the average molecular weight reached a maximum of 37000 for equimolar concentration of monomers. Polymerization was not sensitive to the temperature in the range of -20 to $+60^{\circ} \mathrm{C}$. It was found that side reactions proceeded as well and that $-\mathrm{Se}$-Se- bonds were present in the polymer (one in ca. eighty repeating units). The content of such bonds did not change the conductivity of the obtained polymers, which was $c a .10^{-10} \mathrm{~S} \mathrm{~cm}^{-1}$. In two subsequent publications the authors studied the kinetics of the addition reaction and the effect of substituents in ethynylbenzene as a model for addition polymerization in order to clarify the details of addition polymerization of 1,4-benzenediselenol and 1,4diethynylbenzene. ${ }^{13,14}$

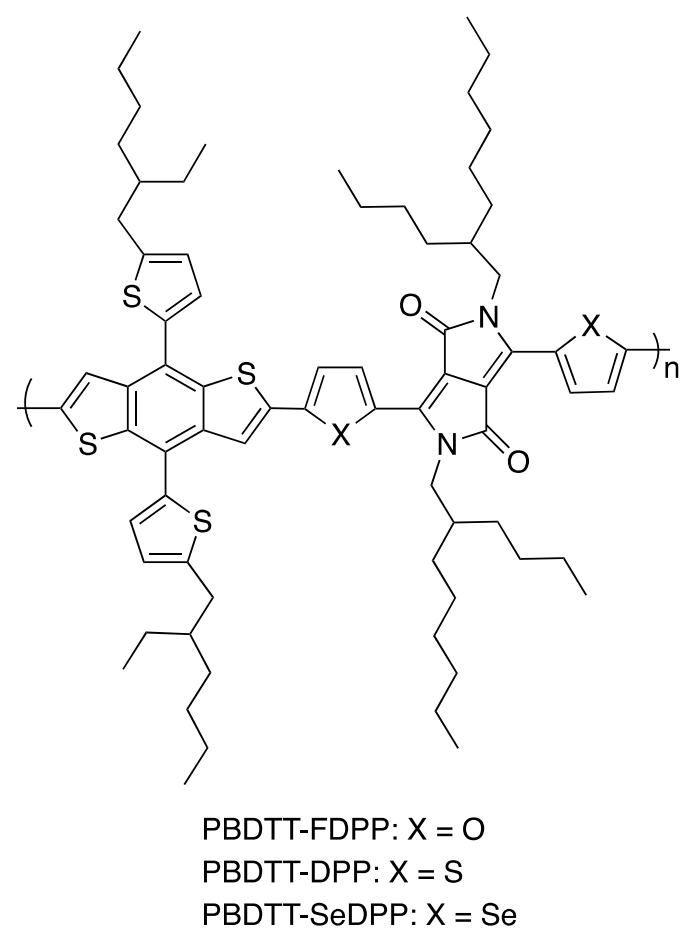

Figure 1. Conducting polymers studied by Dou et al. $^{15}$ 
As can be seen from the above, none of the Se-containing polymers, even these with conjugated double bonds, had a high conductivity. However, a decade later much attention was paid to the incorporation of Se into conducting polymers. It turned out that Se can be used to tune the physicochemical characteristics of polymers that have been used in photovoltaic devices. Dou et al. compared a newly designed polymer, poly[2,6'-4,8-di-(5-ethylhexylthienyl)benzo[1,2-b;3,4-b']dithiophene-alt-2,5-bis(2-butyloctyl)-3,6-bis(selenophene2-yl)pyrrolo[3,4-c]pyrrole-1,4-dione 3 with its sulfur- and oxygen-containing analogs (Figure 1)..$^{15}$ All three polymers were synthesized using the same methodology and GPC showed that all had number average molecular weight around $38000 \mathrm{Da}$ and similar polydispersity index of 2.1.

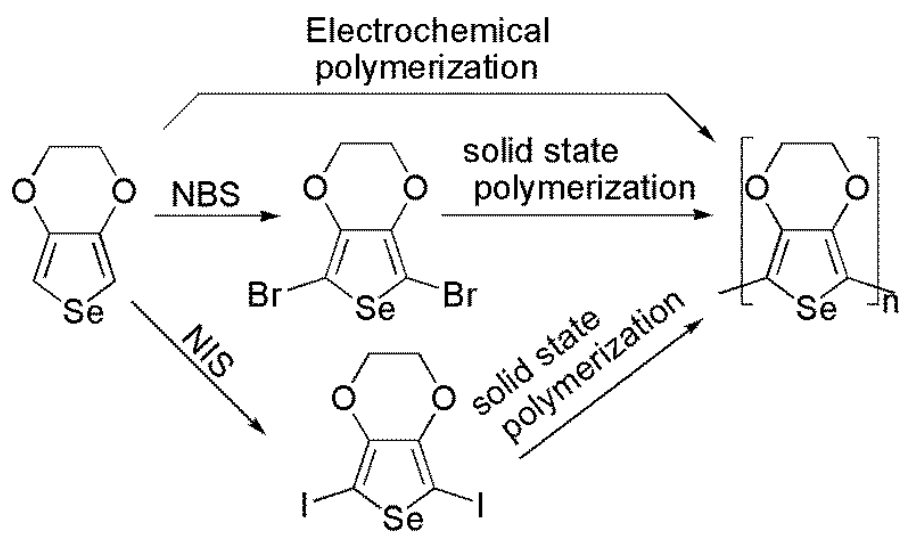

Scheme 2. Poly(3,4-ethylenedioxyselenophene) conducting polymers studied by Patra et al. ${ }^{16}$

In order to obtain highly conductive polymers solid polymerization procedure had been developed and applied to bromo- and iodo- derivatives of 3,4-ethylenedioxyselenophene ${ }^{16}$ (see Scheme 2). The exact molecular weight was not measured directly but it was found that the highest fragments in MALDI MS analysis were up to 20-mers. This is significantly more than it was in the case of poly(3,4-ethylenedioxythiophene). Also, the conductivity of poly(3,4-ethylenedioxyselenophene) obtained from the bromo derivative was high: 3-7 S cm${ }^{-1}$, however due to the bromine dopant. In the case of iodine dopant the conductivity was even higher $-\mathrm{ca} .30 \mathrm{~S}$ $\mathrm{cm}^{-1}$. After dedoping the measurements done under protective atmosphere gave the conductivity below $10^{-3}$ $\mathrm{S} \mathrm{cm}^{-1}$.

It turned out to be possible to improve charge transport properties and lower the bandgap at the same time and that Se-containing polymer could be used in solar cells and visibly-transparent solar cells with power conversion efficiency of $9.5 \%$ and $4.5 \%$, respectively, which is better by $10 \%$ than the efficiency reached with the sulfur analog. Earlier reported polymers, such as poly-(3-hexylselenophene), showed a lower band gap but also lower power conversion efficiency than it is in the well-known sulfur containing analog - poly-(3hexylthiophene). ${ }^{17} \mathrm{~A}$ regioregular poly-(3-hexylselenophene) of relatively high molecular weight of 70000 200000 was reported. ${ }^{18}$ Another regioregular poly(selenophene), this time dodecyl-containing, was obtained with much lower $\mathrm{MW}$ in the range of 19000 to $24000 \mathrm{Da} .{ }^{19}$ Very interesting polymers with Se were also reported in which selenium was a replacement for one sulfur or two sulfur atoms in the monomeric unit (Figure 2). ${ }^{20}$ Depending on the position of the replacement of $\mathrm{S}$ by Se it was possible to lower or increase the band gap. 


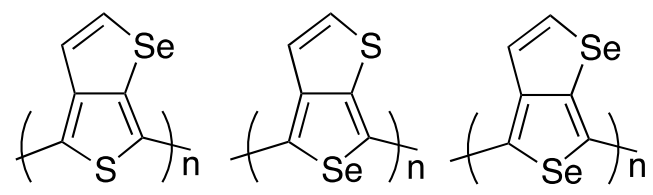

Figure 2. Fused thiophene/selenophene-based polymers. ${ }^{20}$

Selenium was also used to tune the molecular orbital energy level ${ }^{21}$ of the earlier obtained conjugated polymers consisting of alternating thiophene and quinoxaline units (Scheme 3). ${ }^{22}$
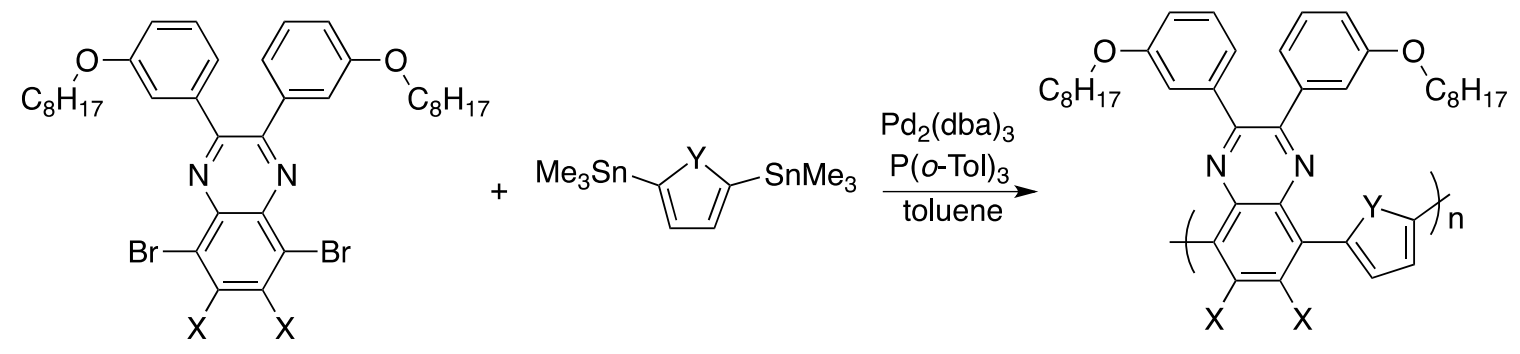

$$
\begin{aligned}
& \text { PTQ: } X=H, Y=S \\
& \text { PTQF2: } X=F, Y=S \\
& \text { PSeQ: } X=H, Y=S e \\
& \text { PSeQF2: } X=F, Y=S e
\end{aligned}
$$

Scheme 3. Synthesis of polymers containing alternating quinoxaline and thiophene or selenophene moieties. ${ }^{22}$

Upon replacement of S by Se the number average molecular weight dropped from 46000 to 37000 but more importantly the polydispersity index increased from 2.6 to 9.7, which may complicate processing of such polymers. The influence of Se atoms, their position in side chains, electron-withdrawing units and $\pi$-bridge on the structural, optical and electronic properties of donor acceptor conjugated polymers of benzodithiophene and 2,1,3-benzoxadiazole was analyzed by Jiang et al. (Figure 3). ${ }^{23}$

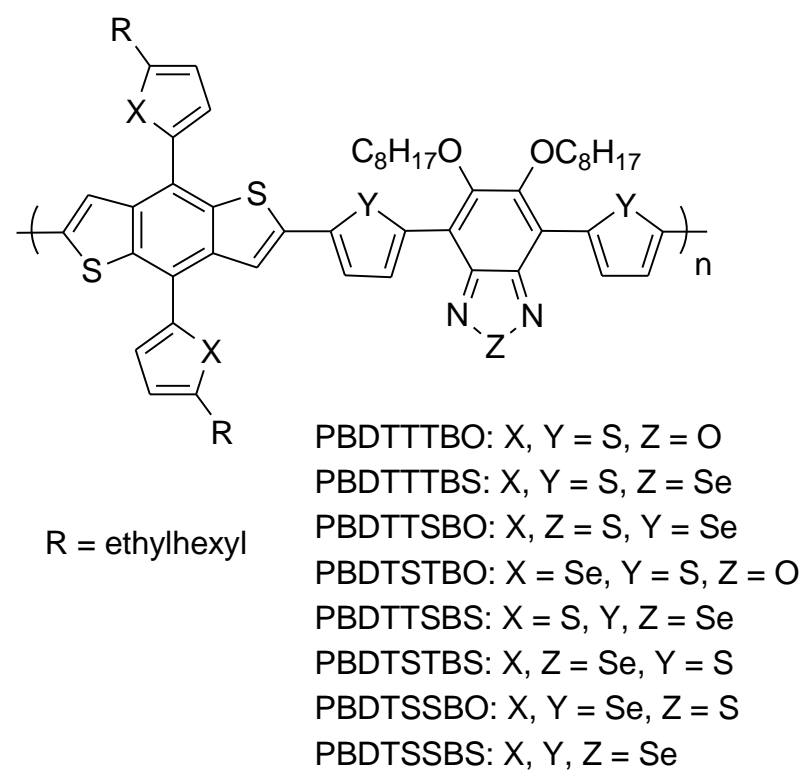

Figure 3. Copolymers of benzodithiophene and heterocycles containing oxygen, sulfur or selenium atoms. ${ }^{23}$ 
All polymers were obtained in good or very good yields ranging from 60 to $80 \%$. Size-exclusion chromatography gave the number average molecular weight in the range of 31000 to $67300 \mathrm{Da}$. The polydispersity index varied from 2.8 to 4.1 , the lower value was obtained for a polymer in which all sulfur was replaced with Se atoms. ${ }^{23}$ Another type of $\pi$-conjugated copolymers, substituted diketopyrrolopyrrole and thiophene was modified by introduction of selenophene (Scheme 4). ${ }^{24}$

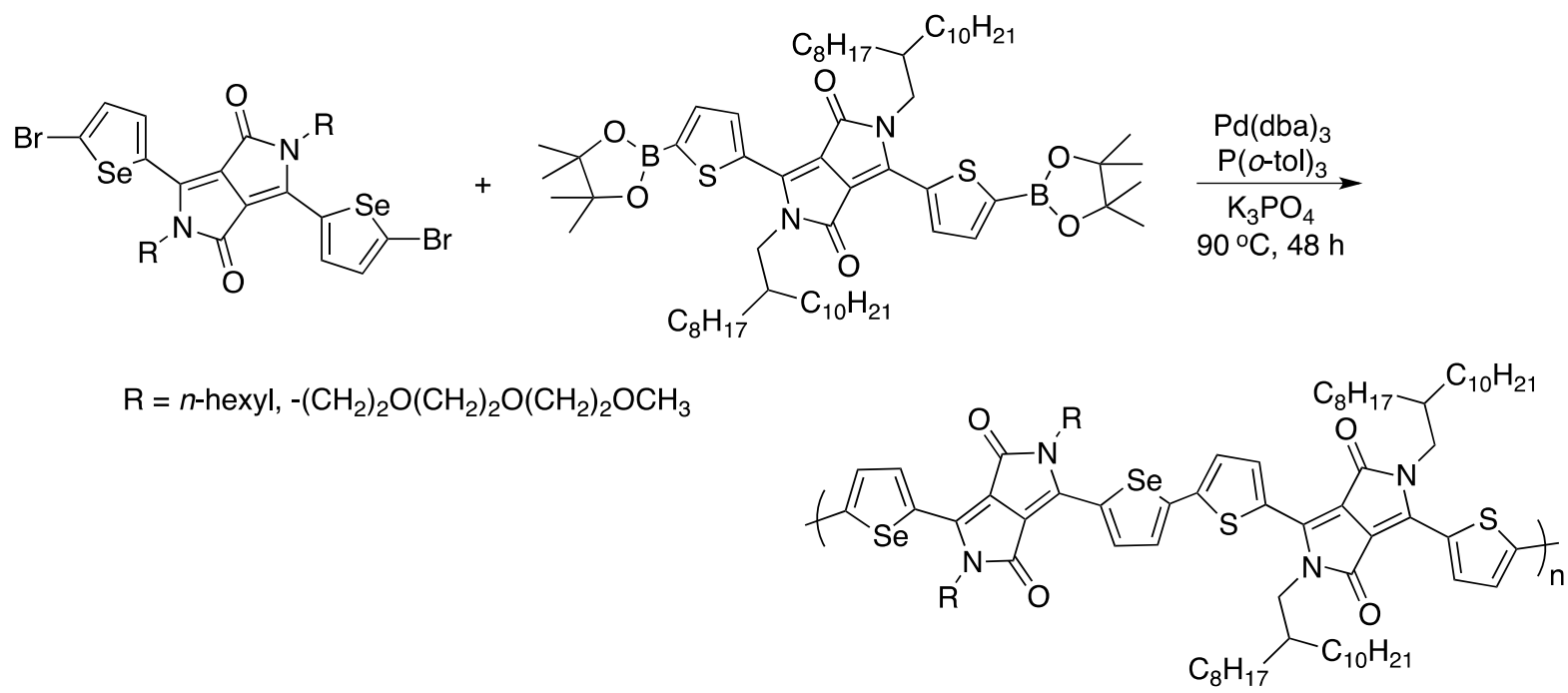

PTDPPSeDPP-R

Scheme 4. Synthesis of diketopyrrolopyrrole-thiophene-selenophene copolymers. ${ }^{24}$

The authors concluded that electron mobility in selenium containing polymers is lower than in sulfur containing ones. ${ }^{24}$

Another type of semiconducting polymer was reported by Jenekhe and co-workers, with alternating naphthalene diimide and either biselenophene or selenophene units (Figure 4). ${ }^{25,26}$

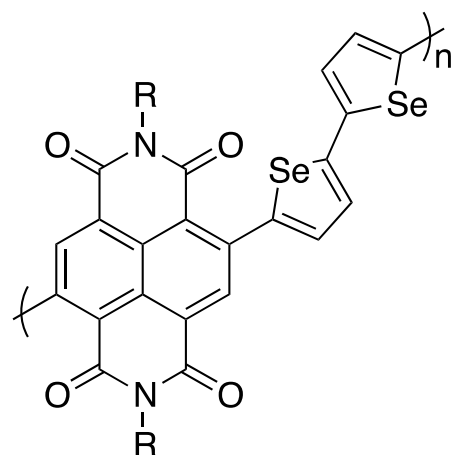

PNDIBS: $R=2$-decyltetradecyl<smiles>[R]N1C(=O)c2cc(-c3ccc(C)[se]3)c3c4c(cc(C)c(c24)C1=O)C(=O)N([R])C3=O</smiles>

PNDIS: $R=2$-decyltetradecyl PNDIS-HD: $R=2$-hexyldecyl

Figure 4. Copolymers of naphthalene diimide and selenophene or biselenophene. ${ }^{25,26}$

The copolymer containing biselenophene was fully characterized and possessed a number average molecular weight of $42400 \mathrm{Da}$ and weight average molecular weight of $110100 \mathrm{Da}$ that gave $\mathrm{PI}=2.6$. 
Interestingly, this type of polymer with Se had almost two times higher MW than its sulfur-containing counterpart, but also a higher PI. ${ }^{25}$ The presence of Se resulted in the increased absorption of light in the NIR region. The copolymer with selenophene units had both molecular weights lower than that with biselenophene $-M_{n}=26100$ and $M_{w}=31600 \mathrm{Da}$, which gave $\mathrm{PI}=1.2$, an extremely low value. ${ }^{26}$

Another group of polymers containing benzoselenadiazole was obtained and tested for application in photovoltaic systems. ${ }^{27}$ They displayed enhanced absorption at shorter wavelengths than polymers with sulfur atoms. The number average molecular weight of benzoselenadiazole-based polymers was 41360 and 31150 $\mathrm{Da}$, whereas polydispersity index was 4.86 and 4.21. Other properties such as thermal stability were very similar $\left(\mathrm{ca} .305^{\circ} \mathrm{C}\right)$ for all Se and S-containing materials. Same benzoselenadiazole units were reported in copolymers designed as an acceptor for solar cells. ${ }^{28}$ It should be noted that the polymer contained also a germanium atom. The molecular weight was low $\left(\mathrm{M}_{n}=6900\right.$ and $\left.\mathrm{M}_{w}=10500, \mathrm{Pl}=1.52\right)$. The ability of selenium to increase intramolecular interactions and enhance carrier transport in conjugated polymers (when compared to sulfur) led to the design and synthesis of polymer with 1,3-di(thiophen-2-yl)selenopheno[3',4':4,5]benzo[1,2-c]thiophene-4,8-dione unit. ${ }^{29}$ Another Se-containing polymer, this time with selenadiazole replacing one of the thiadiazoles in the benzobis[2,1,3]thiadiazole unit was described by Michinobu and co-workers (Scheme 5). ${ }^{30}$ Polymers had very low molecular weight of ca. 10000 and those with the Se atom were less thermally stable that their $\mathrm{S}$ containing analogs.

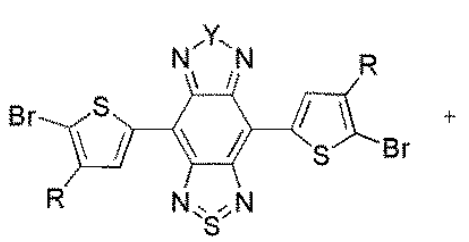

SN: $\mathrm{R}=n$-octyl, $Y=S$ SeN: $R=n$-octyl, $Y=S e$ BBT: $R=2$-butyloctyl, $Y=S$

SeS: $R=2$-butyloctyl, $Y=S e$

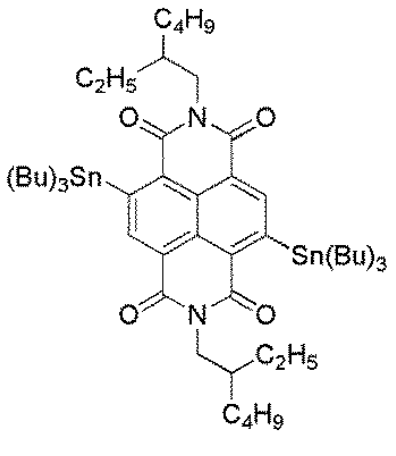

NDI-Sn
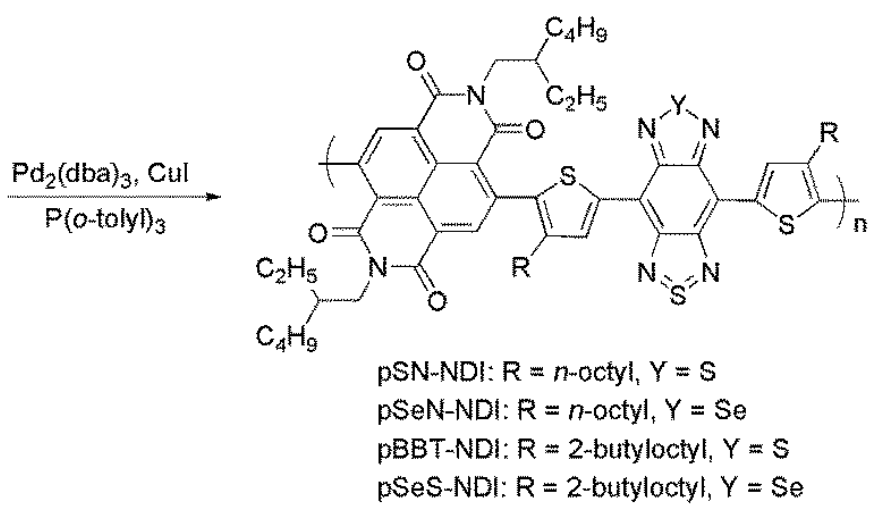

Scheme 5. Synthesis of polymers containing fused thiadiazole and selenadiazole subunits. ${ }^{30}$

Se-only containing polymers with diselenophene-substituted benzoselenadiazole were theoretically designed by Kaya and Kayi. ${ }^{31}$ Selenophene in the main chain of $\pi$-conjugated polymers was reported with $M_{n}=$ 48000 and $M_{w}=107000$ and power conversion efficiency reaching almost 10\% (Scheme 6). ${ }^{32}$ 

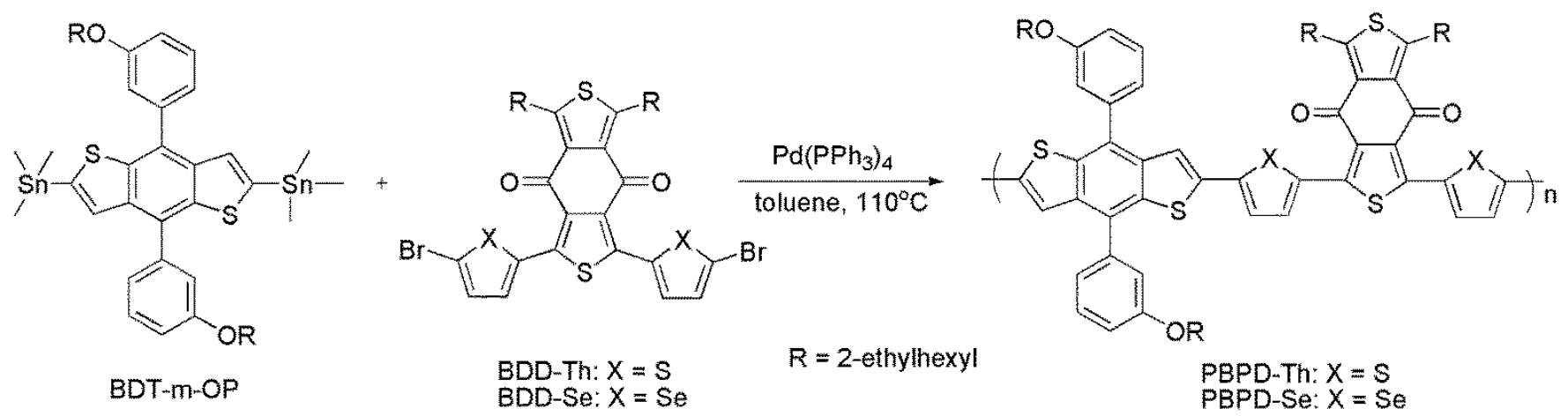

Scheme 6. Synthesis of polymers with thiophene or selenophene unit in the main chain. ${ }^{32}$

A negative effect of the introduction of selenium into the oxindole-based $\pi$-conjugated polymers was recently reported (Scheme 7). ${ }^{33}$ Upon incorporation of selenophene into the main chain the optical absorption decreased compared to the sulfur-containing analogs giving poorer photon harvesting. However, Se polymers were characterized by a high molecular weight of 122200 and $181700 \mathrm{Da}$ (depending on the position of selenophene in the chain).
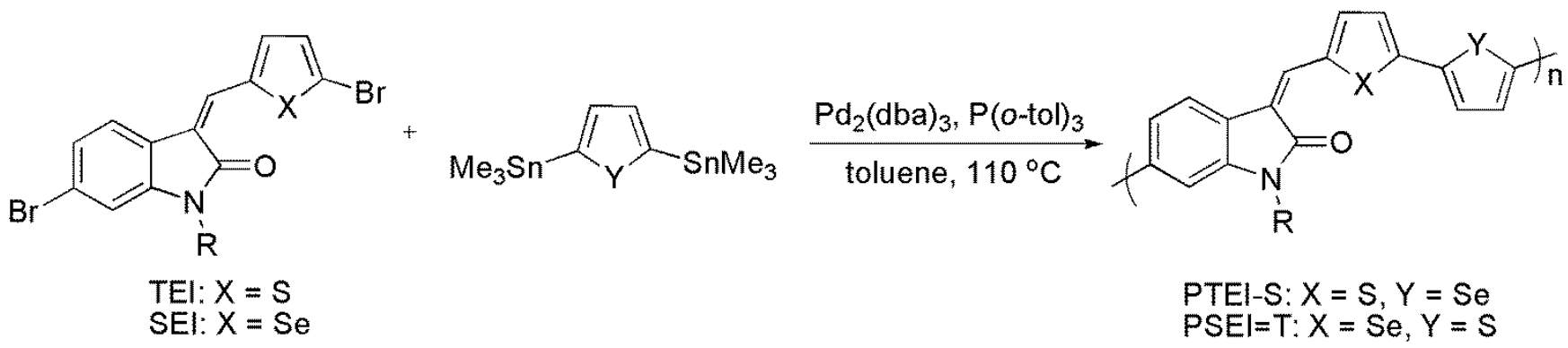

Scheme 7. Preparation of oxindole-based conjugated polymers. ${ }^{33}$

\section{Selenium Compounds as RAFT Agents}

Another field of polymer chemistry where selenium-containing compounds and selenium-containing polymers were investigated is controlled radical polymerization (CRP). This is a general term used for many methods of polymerization, such as, for example, atom transfer radical polymerization (ATRP), and reversible additionfragmentation chain transfer polymerization (RAFT). The common feature of all CRPs is to keep a low concentration of propagating chains and thus minimize termination through recombination of macroradicals. To this end, it is necessary to establish an equilibrium between active radicals and their dormant, non-active form. One of the most frequently used compounds for this purpose are dithiocarbonyls. Quite soon it was realized that since Se has properties similar to these of $S$, initiators can be prepared with the Se atoms and in such a way Se can be introduced to the polymeric chains. A simple route to Se-containing poly(styrene) was presented with the use of a new initiation system, 1-(phenylseleno)ethylbenzene/tert-butyl diphenyl (phenylseleno)silane. ${ }^{34}$ A polymer was obtained with a yield and $M_{n}$ proportional to the reaction time, thus 
evidencing the living radical mechanism. A RAFT mechanism was suggested in the polymerization of styrene in the presence of phosphinodiselenoic esters ${ }^{35}$ and in the presence of $P, P$-diphenyl phosphinodiselenoic acid benzyl ester. ${ }^{36}$ Earlier photopolymerization of styrene with diphenyldiselenide afforded polystyrene with phenylseleno groups at both end of chains. ${ }^{37} \mathrm{~A}$ cyclic compound, 5,5-dimethyl-3-phenyl-2-selenoxo-1,3selenazolidin-4-one (Figure 5), was used in the RAFT polymerization of vinyl acetate. ${ }^{38}$ The authors reported a slightly lower polydispersity index of poly(vinyl acetate) in the case of a selenium-containing chain transfer agent than in the case of sulfur-containing analog.

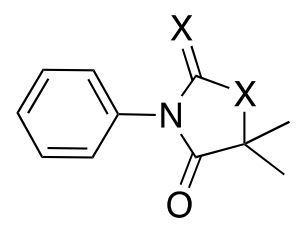

RAFT-S: $X=S$

RAFT-Se: $X=S e$

Figure 5. Cyclic RAFT agents containing sulfur or selenium atoms. ${ }^{38}$

Another RAFT agent, 4-cyanopentanoic acid diselenobenzoate was used in the controlled polymerization of 4-vinylpyridine. ${ }^{39}$ The agent was immobilized on the surface of silicon and the poly(vinyl pyridine) chains were growing from the surface. The MW was proportional to the conversion and the density of pVP brushes was estimated at 0.51 chains $/ \mathrm{nm}^{2}$. An interesting example of incorporation of Se into polymeric chains was

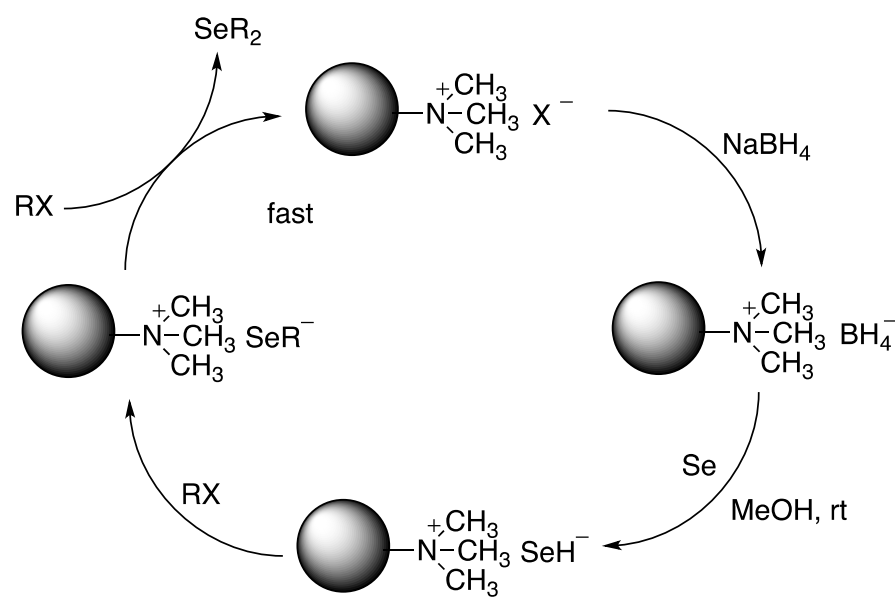

$\mathrm{X}=$ halogen or dithiocarbonyl group, $\mathrm{RX}=$<smiles>CCOC(=O)C(C)(C)C[C@H](Br)C(=O)OC</smiles>

$\mathrm{PMA}-\mathrm{Br}$<smiles>CC(C)(C)CC(SC(=S)c1cccc2ccccc12)c1ccccc1</smiles><smiles>CC(CC(Br)c1ccccc1)c1ccc(C(C)CC(Br)c2ccccc2)cc1</smiles><smiles>CCOC(=O)C(C)C[C@H](C)SC(=S)OCC</smiles><smiles>CCOC(=O)C(C)C[C@H](SC(=S)OCC)N1CCCC1=O</smiles>

Scheme 8. The application of ion-exchange resin to the synthesis of selenium-containing polymers. ${ }^{41}$ 
reported by Zeng et $a l .{ }^{40}$ In the polymerization of styrene and methyl methacrylate seleno-functionalities were introduced into the polymer backbone, in the middle of the chain. The oxidation treatment of such polymers gave half-molecular weight polymers with vinyl-terminated chain ends. This material could be used in further modifications such as in thiol-ene click reactions. An interesting approach to the synthesis of topological selenium-containing polymers, involving the use of borohydride ion-exchange resin to react with Se and serve as a source of this element, has been reported (Scheme 8). ${ }^{41}$

By methods such as those described above, both the topology and the MW of the product can be controlled by the proper choice of the polymeric precursor.

Diselenide-containing polymers were also prepared from alkenes; Scheme 9 shows the electrophilic process. ${ }^{42}$ Diselenides were formed through the alcoholysis of selenolactone. The reaction proceeded in high yield; however, the MW of such polymers depended to a great extent on the type of alcohol and varied from 500 Da to 25000 Da.

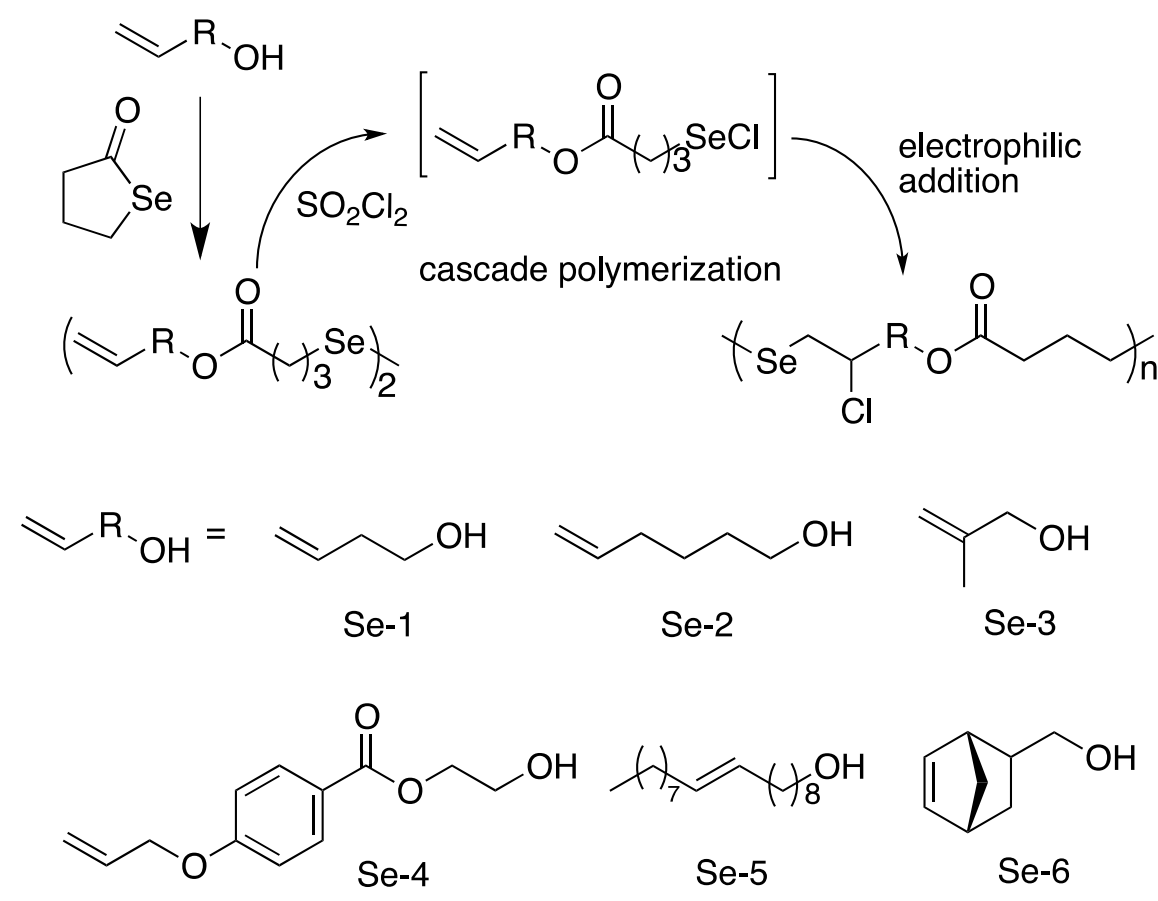

Scheme 9. Preparation of diselenide-containing polymers. ${ }^{42}$

Copolymers of variously substituted maleimide and styrene were synthesized with the aim of obtaining material of high refractive index. ${ }^{43}$ Because selenium possesses very high molar refraction $[R]_{s e}=11.17$, it was decided to incorporate $\mathrm{Se}$ into the side group in $\mathrm{N}$-maleimide or in both $\mathrm{N}$-maleimide as well as in the styrene units (Figure 6). The latter approach resulted in a Se containing copolymer with very high refractive index of 1.869 (for $\lambda=633 \mathrm{~nm}$ ). Since RAFT polymerization was used in the preparation of polymers their MW could be controlled precisely and authors reported MW $=9300$ to $27300 \mathrm{Da}$. 

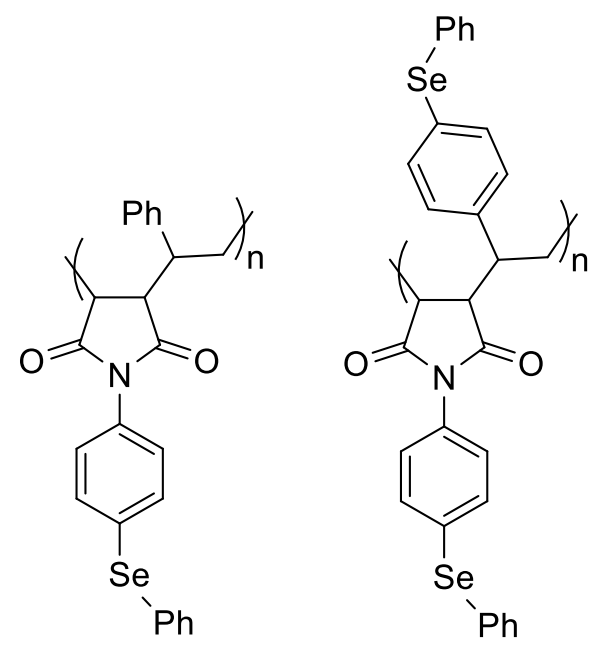

Figure 6. Maleimide-based selenium-containing polymers. ${ }^{43}$

\section{Application of Selenium-containing Polymers in Chemical Synthesis}

Though selenium-containing polymers have been known for many years, the first report on the application of such polymers in organic synthesis comes from 1976, ${ }^{44}$ and for many years the area has remained relatively undeveloped. However, the growing interest in the application of organoselenium compounds in organic synthesis resulted in the first attempts of the use of supported reactants of this kind. It is well known that polymer-bound chemicals offer a convenience in handling, especially during work-up which usually consists of washing off the unwanted components, and filtration of resin after the product release. This way, lengthy and expensive purification procedures can be avoided. A special advantage of immobilized selenium reagents as compared the solution chemistry lies in their decreased volatility, which results in much lower toxicity and in reduced odor.

Organoselenium reagents and catalysts are widely used in organic synthesis, mainly due to relative ease of carbon-selenium bond cleavage. ${ }^{45-48}$ This versatility is also demonstrated by the variety of applications of immobilized compounds containing this element.

Nicolaou and coworkers prepared a set of useful polystyrene-bound selenium reagents from readily available starting materials: lithiation followed by reaction with MeSeSeMe afforded a methyl selenidefunctionalized resin, which was further converted into other derivatives (Scheme 10). ${ }^{49}$ Among them, a brominated derivative was later found to be a versatile, stable and convenient starting material for use in selenium-mediated solid-phase synthesis (vide infra). 


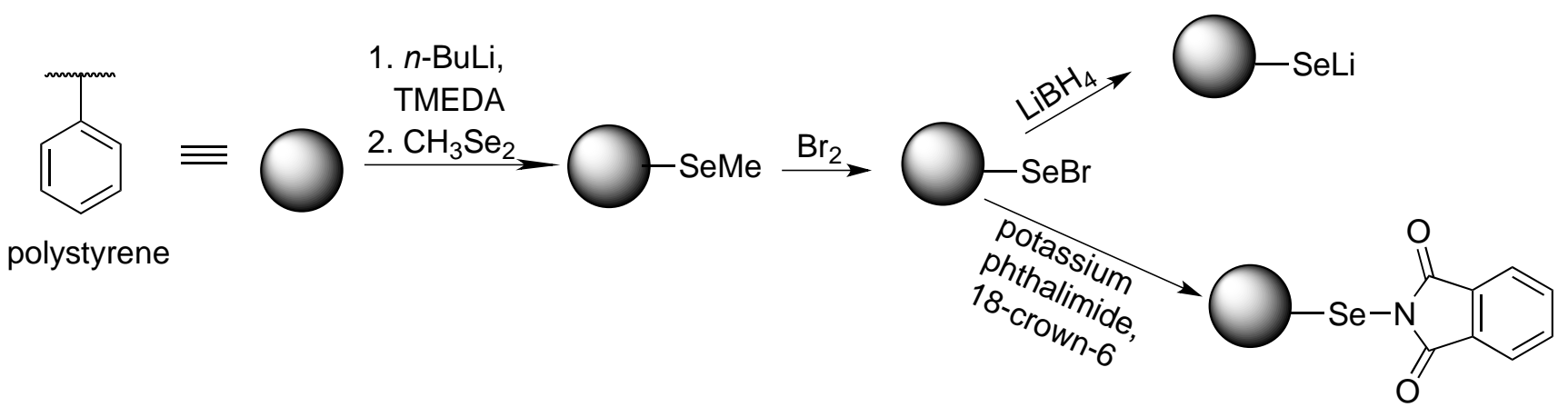

Scheme 10. Preparation of polystyrene-bound selenium reagents. ${ }^{49}$

Nicolaou's group has described applications of their resins for reversible and quantitative binding of olefins as well as their efficient hydration. An interesting diverse stereoselectivity of selenium bromide- and phthalimide-modified polymers was observed for the synthesis of 2-deoxyglycosides. Removal of products from the support was accomplished by free radical chemistry $\left(\mathrm{Bu}_{3} \mathrm{SnH}+\mathrm{AIBN}\right)$ or, in one case, by the action of $\mathrm{H}_{2} \mathrm{O}_{2}$.

Another example of application of selenium-containing polymers in solid-phase stereoselective synthesis was described by Uehlin and Wirth. ${ }^{50}$ Chiral electrophilic selenium reagents bound to mesoporous silica were found efficient in enantioselective selenylation of various alkenes (up to $72 \%$ yield, $46-80 \%$ ee, Scheme 11 ).
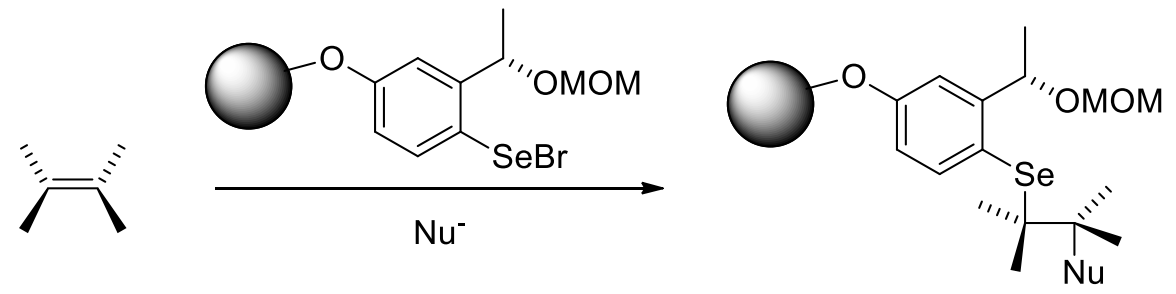

Scheme 11. Selenylation of olefins using immobilized selenium reagents. ${ }^{50}$

The utility of polymer-bound selenium reagents in organic synthesis was further exploited by Sheng and coworkers. They reported on the reaction of polymer-supported selenium bromide with various olefins followed by treatment with alcohol or potassium carboxylate. ${ }^{51}$ The obtained adducts were then oxidatively cleft by the addition of hydrogen peroxide in THF to give corresponding allylic ethers or esters in high yield (75-85\%) and purity, without the need for tedious work-up and purification (Scheme 12). Sheng's group also reported a synthesis of polymer-supported $\alpha$-phenylseleno ketones and esters, from which $\alpha, \beta$-unsaturated ketones and esters were obtained in $74-95 \%$ yield by treatment with $\mathrm{H}_{2} \mathrm{O}_{2}$ (Scheme 13). ${ }^{52}$

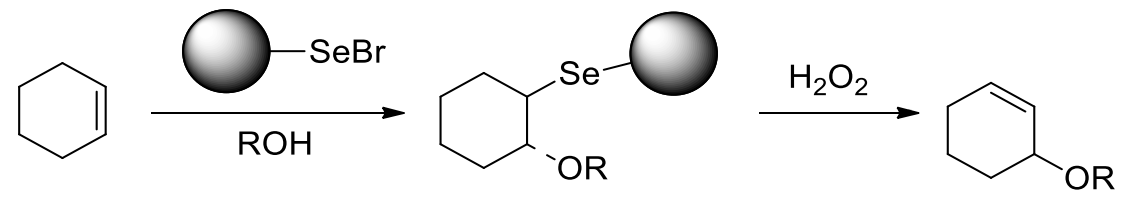

Scheme 12. Preparation of allylic ethers mediated by a supported selenium bromide. ${ }^{51}$ 

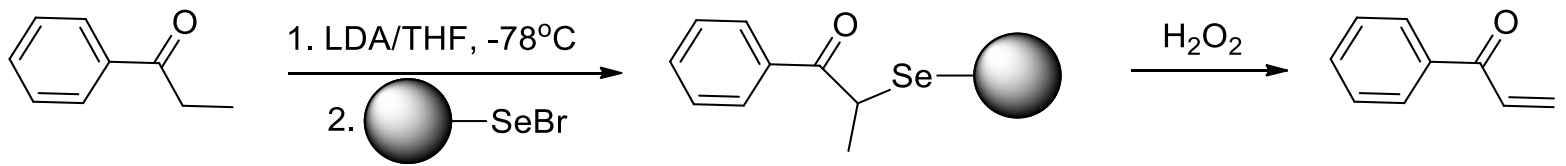

Scheme 13. Application of a polymer-attached selenium reagent in the synthesis of $\alpha, \beta$-unsaturated ketones. ${ }^{52}$

In a continuation of their work, Sheng and coworkers converted selenium bromide attached to crosslinked polystyrene into immobilized $\alpha$-methyl selenopropionate, 2-selenopropiophenone, 1-selenoethyl phenyl sulfone and diethyl 1-selenoethylphosphonate. ${ }^{53}$ Their treatment with LDA and aldehydes, and then removal of products from the support by oxidation-elimination with $\mathrm{H}_{2} \mathrm{O}_{2}$ allowed easy isolation of MoritaBaylis-Hillman adducts in $83-91 \%$ yields (Scheme 14). The possibility of recovery and reuse of the starting selenium bromide resin was also demonstrated. A similar approach (lithiation of supported selenium bromide, reaction with 3-acetoxy-2-methylene-alkanoates) yielded allyl selenide resins, from which (Z)-allyl iodides were obtained in good yields (78-95\%) and high purities (Scheme 15). ${ }^{54}$ This time the product was cleft from the polymer by treatment with methyl iodide, and the starting resin was regenerated by the addition of bromine.

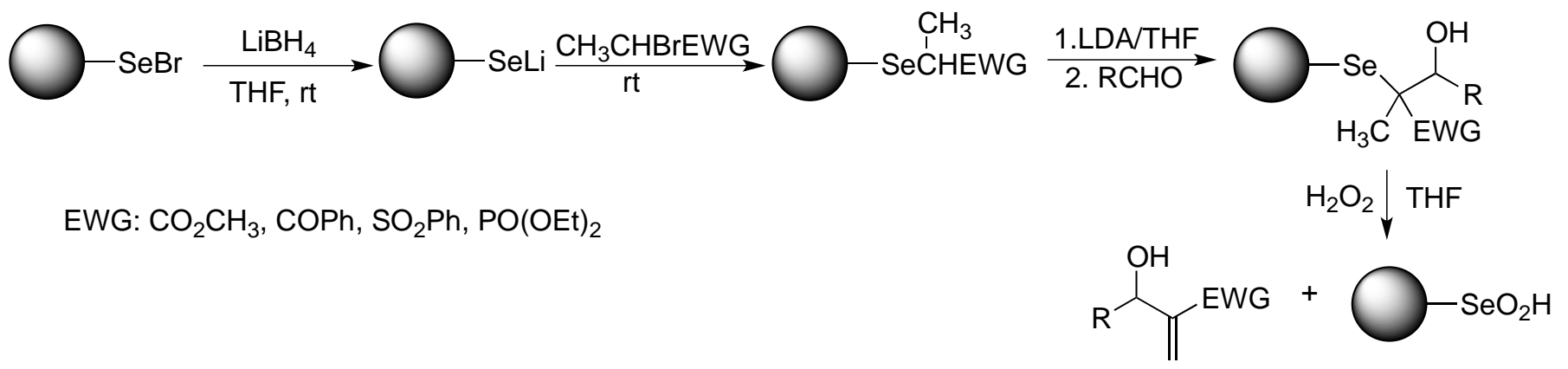

Scheme 14. $\mathrm{MBH}$ reaction mediated by a supported selenium reagent. ${ }^{53}$

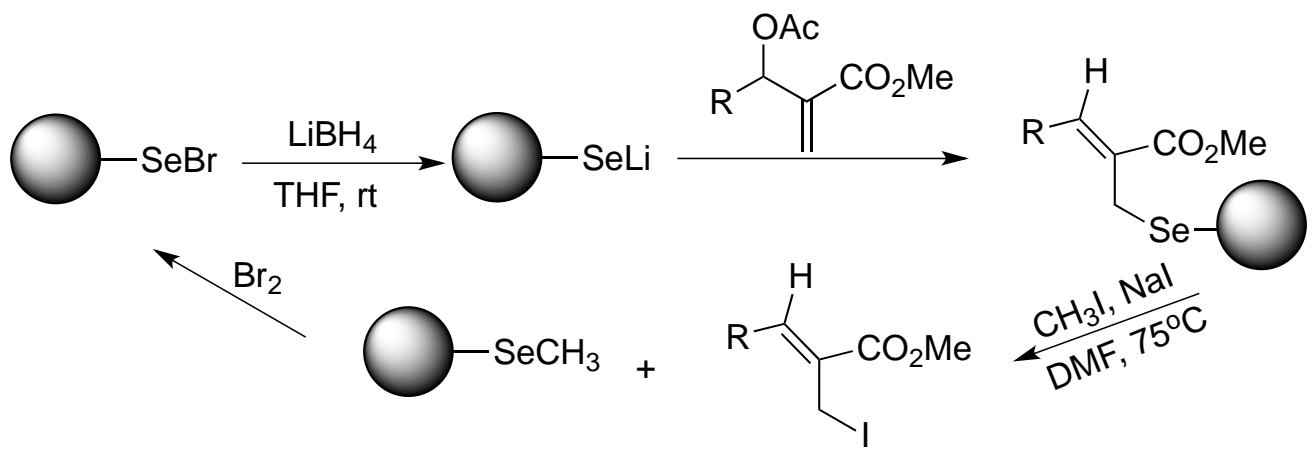

Scheme 15. The use of immobilized selenium reagents in the stereoselective preparation of $(Z)$-allyl iodides. ${ }^{54}$

Selenium-containing polymers have been applied to the efficient synthesis of heterocycles. An intramolecular electrophilic cyclization of $\alpha$-allyl substituted 1,3-dicarbonyl compounds induced by polystyrene-supported selenium bromide yielded polysubstituted dihydrofurans and tetrahydrofurans, as reported by Tang et al (Scheme 16). ${ }^{55}$ Release of the desired product from the polymer was achieved by 
treatment either with hydrogen peroxide or methyl iodide. Yields of the final products were in the range of 76 $89 \%$. The possibility of recovery and reuse of the selenium resin was verified. A solid-phase synthesis of 1-alkyl-2-phenyl-4-quinolones and 2-phenyl-2,3-dihydroquinolin-4(1H)-ones catalyzed by $\mathrm{ZnCl}_{2}$ was reported by Tang et al. (Scheme 17). ${ }^{56}$ In the presence of selenium resin, electrophilic cyclization of chalcones proceeded in high yield, and polymer-bound product could easily be isolated from byproducts and from an excess of reactant.

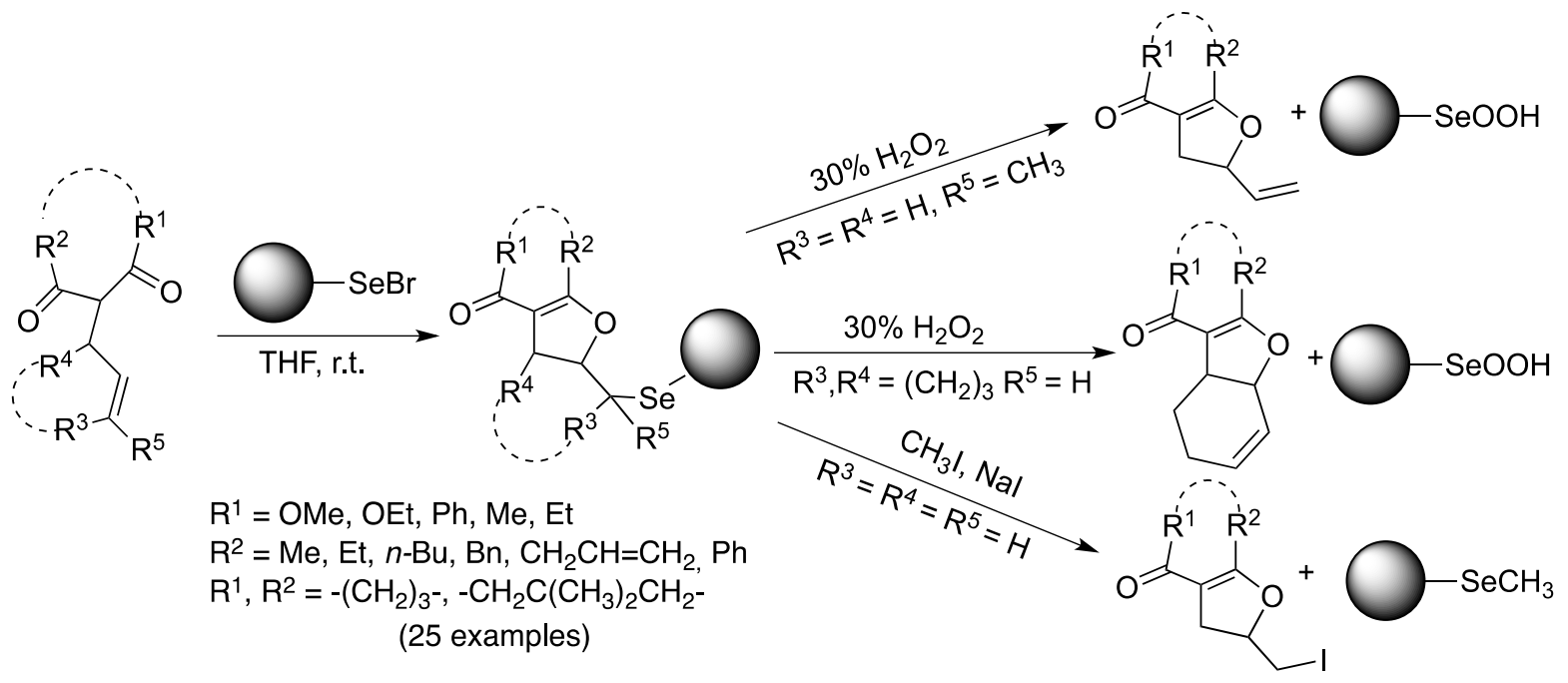

Scheme 16. Synthesis of dihydrofurans with the use of selenium-containing polymers. ${ }^{55}$

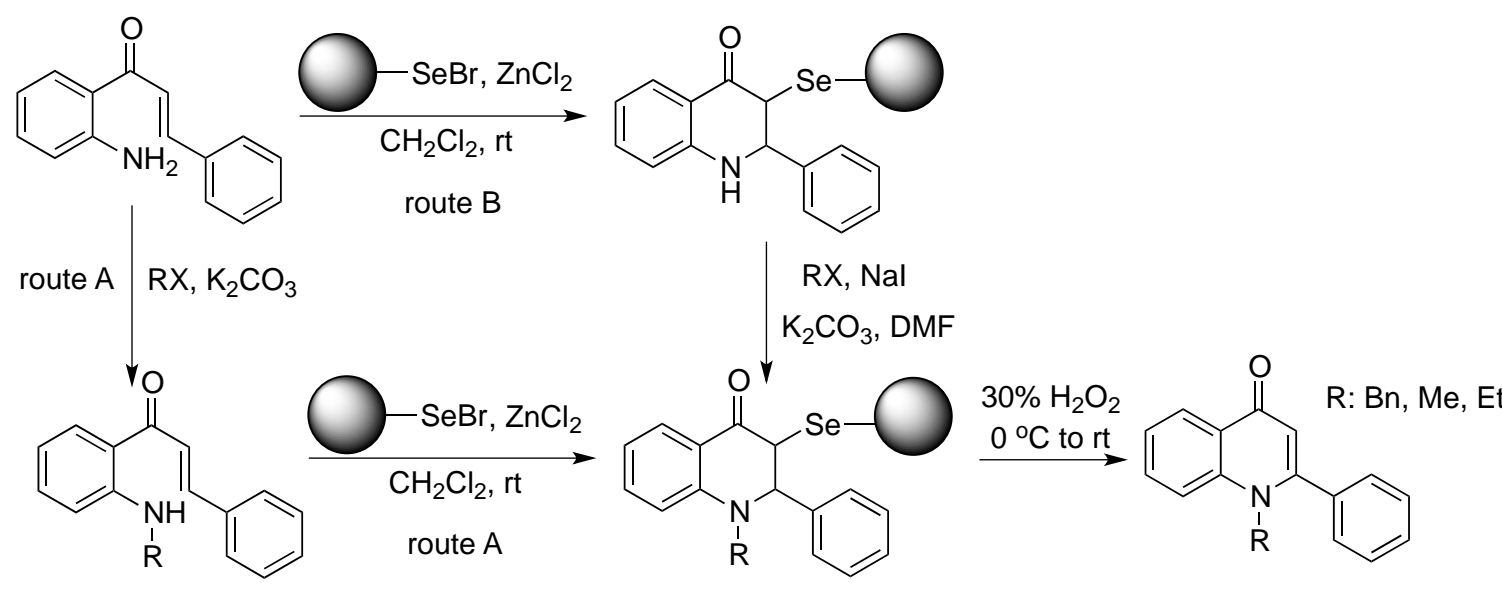

route A: total yield up to $89 \%$ route B: total yield up to $48 \%$

Scheme 17. Solid-phase synthesis of quinolone derivatives. ${ }^{56}$

In their route to a $\gamma$-butyrolactone system, Wang et al. reacted polystyrene-bound selenium bromide with $\gamma, \delta$-unsaturated acids. ${ }^{57} \mathrm{~A}$ stereoselective ring closure (with a preference for syn isomer) was observed, and subsequent reaction with methyl iodide afforded 5-iodomethyl-dihydrofuran-2-ones in 90-96\% yield together with methylated selenium resin, which could be converted back into the parent form (Scheme 18). A click chemistry approach allowed efficient conversion of polystyrene-bound 2-azidoethyl phenyl selenide and 3azidopropyl phenyl selenide with various terminal alkynes into substituted 1-vinyl-and 1-allyl-1,2,3-triazoles 
(80-93\% yield under optimized conditions). ${ }^{58}$ Also, in this synthesis hydrogen peroxide was used for product release (Scheme 19), and the resulting resin-bound seleninic acid was reduced with $\mathrm{KI} / \mathrm{Na}_{2} \mathrm{~S}_{2} \mathrm{O}_{3}$; further treatment with bromine led to recovery of the starting modified polymer which could be used up to three times without significant loss of efficiency.

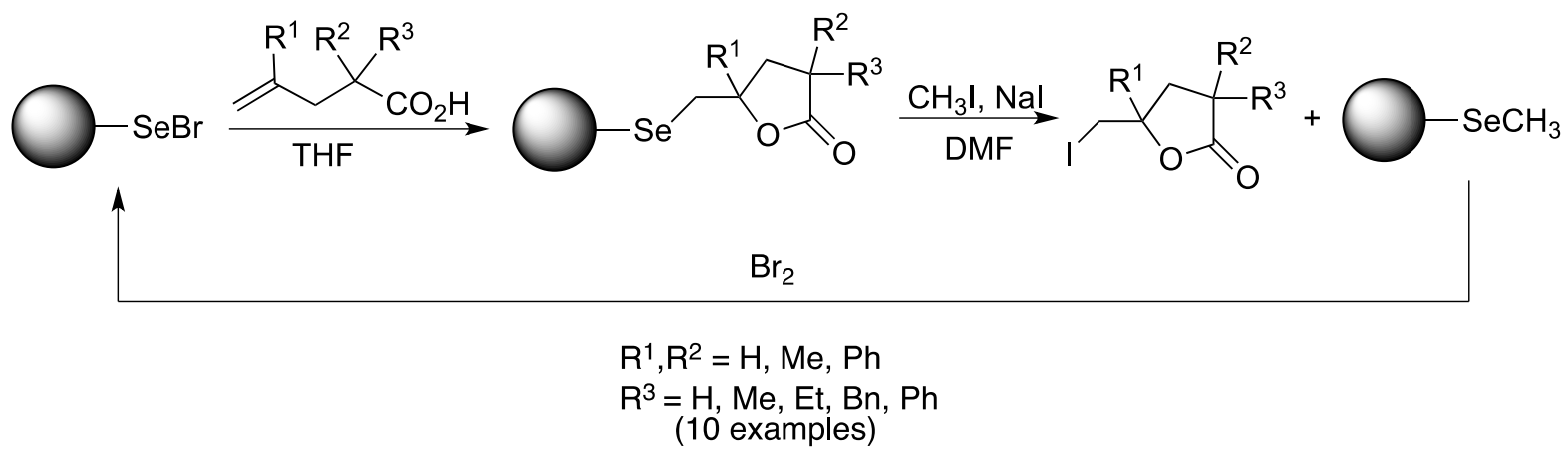

Scheme 18. Selenium-mediated preparation of 5-iodomethyl-dihydrofuran-2-ones. ${ }^{57}$

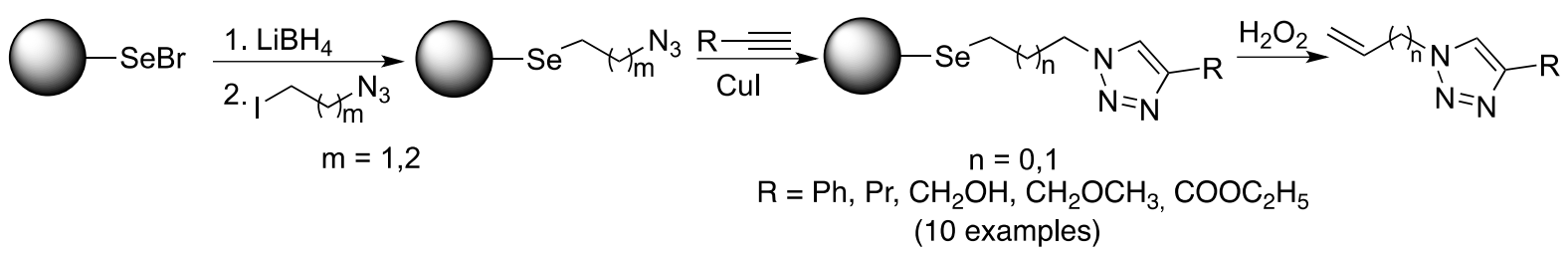

Scheme 19. Click reaction on a polymeric support containing selenium. ${ }^{58}$

\section{Conclusions}

In conclusion: selenium-containing polymers are being explored in three main areas. One of these concerns the synthesis of $\pi$-conjugated polymers, where selenium is in many cases used to replace sulfur atoms and confer new properties to the conducting or semi-conducting polymers. In many cases such replacement gives positive changes of polymer properties, but usually Se-containing polymers are more difficult to prepare and the processing parameters of such polymers (polydispersity index, molecular weight) are not as good as in the case of S-containing analogs. Another important field comprises controlled polymerization, where again Se is used to replace $S$ in the structures of various compounds that modify the equilibrium between active radicals and their dormant, non-active form. Slowing the propagation reaction allows a better control over the polydispersity of resulting polymers. This application of selenium compounds is related to their role in organic chemistry as reagents and catalysts. There are reports on their use in the immobilized form, which facilitates the handling of such materials.

\section{References}

1. Xia, J.; Li, T.; Lu, C.; Xu, H. Macromolecules 2018, 51, 7435-7455.

https://doi.org/10.1021/acs.macromol.8b01597 
2. Patra, A.; Kumar, R.; Chand, S. Isr. J. Chem. 2014, 54, 621-641. https://doi.org/10.1002/iich.201400052

3. Morgan, G. T.; Burstall, F. H. J. Chem. Soc. 1930, 1497-1502. https://doi.org/10.1039/JR9300001497

4. Morgan, G. T.; Burstall, F. H. J. Chem. Soc. 1931, 173-180.

https://doi.org/10.1039/JR9310000173

5. Montillaro, L. C.; Credali, L.; Russo, M.; De Checchi, C. J. Polym. Sci. Part B: Polym. Lett. 1965, 3, $581-585$. https://doi.org/10.1002/pol.1965.110030713

6. Prince, M.; Bremer, B. J. Polym. Sci. Part B: Polym. Lett. 1967, 5, 843-845.

https://doi.org/10.1002/pol.1967.110050921

7. Okamoto, Y.; Yano, T. J. Org. Chem. 1969, 34, 1492-1493.

https://doi.org/10.1021/jo01257a077

8. Keimatsu, S.; Satoda, I. J. Pharm. Soc. Jpn. 1935, 55, 58-66.

https://doi.org/10.1248/yakushi1881.55.1 58

9. Prince, M.; Bremer, B. J. Polym. Sci. Part B: Polym. Lett. 1967, 5, 847-849.

https://doi.org/10.1002/pol.1967.110050922

10. Painter, E. P. J. Am. Chem. Soc. 1947, 69, 232-234.

https://doi.org/10.1021/ja01194a014

11. Kobayashi, E.; Akiba, Y.; Aoshima, S. J. Polym. Sci. Part A, Polym.Chem. 1994, 32, 1609-1617. https://doi.org/10.1002/pola.1994.080320902

12. Kobayashi, E.; Metaka, N.; Aoshima, S.; Furukawa, J. Polym. J. 1995, 27, 147-155. https://doi.org/10.1295/polymj.27.147

13. Metaka, N.; Kobayashi, E.; Aoshima, S.; Furukawa, J. Polym. J. 1995, 27, 156-164.

https://doi.org/10.1295/polymj.27.156

14. Metaka, N.; Kobayashi, E.; Aoshima, S.; Furukawa, J. Polym. J. 1995, 27, 683-693. https://doi.org/10.1295/polymj.27.683

15. Dou, L.; Chang, W.-H.; Gao, J.; Chen, C.-C.; You, J.; Yang, Y. Adv. Mater. 2013, 25, 825-831., https://doi.org/10.1002/adma.201203827

16. Patra, A. ; Wijsboom, Y.H. ; Zade, S.S. ; Li.M. ; Sheynin,Y. ; Leitus, G. ; Bendikov, M. J.Am.Chem.Soc. 2008, 130, 6734-6736.

https://doi.org/10.1021/ja8018675

17. Ballantyne, A. M.; Chen, L.; Nelson, J.; Bradley, D. D. C.; Astuti. Y.; Maurano, A.; Shuttle, C. G.; Durrant, J. R.; Heeney, M.; Duffy, W.; McCulloch, I. Adv. Mater. 2007, 19, 4544-4347.

https://doi.org/10.1002/adma.200701265

18. Heeney, M.; Zhang, W.; Crouch, D. J.; Chabinyc, M. L.; Gordeyev, S.; Hamilton, R.; Higgins, S. J.; McCulloch, I.; Skabara, P. J.; Sparrowe, D.; Tierney, S. Chem. Commun. 2007, 5061-5063.

https://doi.org/10.1039/b712398a

19. Lee, W.-H. Lee, S. K.; Son, S. K.; Choi, J.-E.; Shin, W. S.; Kim, K.; Lee, S.-H.; Moon, S.-J.; Kang, I.-N. J. Polym. Sci., Part A: Polym. Chem. 2012, 50, 551-561.

https://doi.org/10.1002/pola.25064

20. Patra, A.; Wijsboom, Y. H.; Leitus, G.; Bendikov, M. Chem. Mater. 2011, 23, 896-906. https://doi.org/10.1021/cm102395v

21. Zhuang, W.; Zhen, H.; Kroon, R.; Tang, Z.; Hellström, S.; Hou, L.; Wang, E.; Gedefaw, D.; Inganäs, O.; Zhang, F.; Andersson, M. R. J. Mater. Chem. A. 2013, 1, 13422-13425. 
https://doi.org/10.1039/c3ta13040a

22. Wang, E.; Hou, L.; Wang, Z.; Hellström, S.; Zhang, F.; Inganäs, O.; Andersson, M. R. Adv. Mater. 2010, 22, 5240-5244.

https://doi.org/10.1002/adma.201002225

23. Jiang, J.-M.; Raghunath, P.; Lin, H.-K.; Lin, Y.-C.; Lin, M. C.; Wei, K.-H. Macromolecules 2014, 47, 70707080.

https://doi.org/10.1021/ma501720k

24. Dhar, J.; Kanimozhi, C.; Yacobi-Gross, N.; Anthopoulos, T. D.; Salzner, U. Patil, S. Isr. J. Chem. 2014, 54, 817-827.

https://doi.org/10.1002/ijch.201400051

25. Hwang, Y.-J.; Ren, G.; Murari, N. M.; Jenekhe, S. A. Macromolecules 2012, 45, 9056-9062.

https://doi.org/10.1021/ma3020239

26. Earmme, T.; Hwang, Y.-J.; Murari, N. M.; Subramaniyan, S.; Jenekhe, S. A. J. Am. Chem. Soc. 2013, 135, 14960-14963.

https://doi.org/10.1021/ia4085429

27. Yu, J.; Ding, G.; Hai, J.; Zhu, E.; Yin, X.; Xu, Z.; Zhou, B.; Zhang, F.; Ma, W.; Tang, W. Phys. Chem. Chem.

Phys. 2016, 18, 7978-7986.

https://doi.org/10.1039/C5CP07942J

28. Fang, H.-W.; Hsu, S. L.-C. Polym. Eng. Sci. 2018, 387-394.

https://doi.org/10.1002/pen.24585

29. Liu, T.; Meng, D.; Cai, Y.; Sun, X.; Li, Y.; Huo, L.; Liu, F.; Wang, Z.; Russell, T. P.; Sun, Y. Adv. Sci. 2016, 3, 1600117.

https://doi.org/10.1002/advs.201600117

30. Wang, Y.; Hasegawa, T.; Matsumoto, H.; Mori, T.; Michinobu, T. Adv. Funct. Mater. 2017, $27,1701486$. https://doi.org/10.1002/adfm.201701486

31. Kaya, B.; Kayi, H. Comput. Theor. Chem. 2017, 1099, 45-54.

https://doi.org/10.1016/j.comptc.2016.11.014

32. Xu, Z.; Fan, Q.; Meng, X.; Guo, X.; Su, W.; Ma, W.; Zhang, M., Li, Y. Chem. Mater. 2017, 29, 4811-4818. https://doi.org/10.1021/acs.chemmater.7b00729

33. Zhao, D.; Zheng, J.; Gong, Z.; Wu, J.; Tang, J.; Zhang, Q. Org. Electron. 2019, 64, 131-137. https://doi.org/10.1016/j.orgel.2018.10.021

34. Rathore, K.; Raghunatha Reddy, K.; Tomer, N. S.; Desai S. M.; Singh, R. P. J. Appl. Polym. Sci. 2004, 93, 348-355.

https://doi.org/10.1002/app.20391

35. Moon, J.; Nam, H.; Kim, S.; Ryu, J.; Han, C.; Lee, C.; Lee, S. Tetrahedron Lett. 2008, 49, 5137-5140. https://doi.org/10.1016/i.tetlet.2008.06.098

36. Zeng, J.; Zhu, J.; Zhang, J.; Pan, X.; Zhang, W.; Cheng, Z.; Zhu, X. J. Polym. Sci. Part A.: Polym. Chem. 2012, 50, 2211-2218.

https://doi.org/10.1002/pola.25994

37. Kwon, T. S.; Kondo, S.; Kunisada, H.; Yuki., Y. Polym. J. 1998, 30, 559-563.

https://doi.org/10.1295/polymi.30.559

38. Zhan, Y.; Zhang, Z.; Pan, X.; Zhu, J. Zhou, N.; Zhu, X. J. Polym. Sci. Part A.: Polym. Chem. 2013, 51, 16561663.

https://doi.org/10.1002/pola.26539 
39. Demirci, S.; Kinali-Demirci, S.; Caykara T. Polymer 2013, 54, 5345-5350. https://doi.org/10.1016/i.polymer.2013.07.060

40. Zeng, J.; Zhang, Z.; Zhu, J.; Zhou, N. Cheng, Z.; Zhu, X. J. Polym. Sci. Part A.: Polym. Chem. 2013, 51, 26062613.

https://doi.org/10.1002/pola.26648

41. Ding, C.; Fan, C.; Pan, X.; Zhang, Z.; Zhu, J.; Zhu, X. Polym. Chem. 2017, 8, 3958-3964. https://doi.org/10.1039/C7PY00676D

42. An, X.; Lu, W.; Pang, M.; Zhang, Z.; Zhu, X.; Zhu, J.; Pan, X. Polym. Chem. 2019, 10, 574-581. https://doi.org/10.1039/C8PY01441H

43. Li, Q.; Ng, K. L.; Pan, X.; Zhu J. Polym. Chem. 2019, 10, 4279-4286. https://doi.org/10.1039/C9PY00660E

44. Michels, R.; Kato, M.; Heitz, W. Makromol. Chem. 1976, 177, 2311-2317. https://doi.org/10.1002/macp.1976.021770808

45. Organoselenium Chemistry: A Practical Approach; Back, T. G., Ed.; Oxford University Press: Oxford, 1999.

46. Organoselenium Chemistry: Synthesis and Reactions; Wirth, T., Ed.; Wiley-VCH: Weinheim, 2012.

47. Organoselenium Chemistry: Between Synthesis and Biochemistry; Santi, C., Ed.; Bentham, 2014.

48. Lenardão, E.; Santi, C.; Sancineto, L. Organoselenium Compounds as Reagents and Catalysts to Develop New Green Protocols, in New Frontiers in Organoselenium Compounds, Springer, Cham, 2018.

https://doi.org/10.1007/978-3-319-92405-2

49. Nicolaou, K. C. Pastor, J.; Barluenga, S.; Winssinger, N. Chem. Commun. 1998, 1947-1948. https://doi.org/10.1039/a804795b

50. Uehlin, L.; Wirth, T. Org. Lett. 2001, 3, 2931-2933.

https://doi.org/10.1021/ol0164435

51. Sheng, S.-R.; Huang, X. J. Chem. Res. (S) 2002, 184-185.

https://doi.org/10.3184/030823402103171609

52. Sheng, S.-R.; Liu, X.-L.; Wang, X.-C. J. Chin. Chem. Soc. 2003, 50, 279-281.

https://doi.org/10.1002/jccs.200300042

53. Huang, B.; Sheng, S.-R.; Huang, Y.-X.; Xin, Q.; Song, L.-Y.; Luo, N.-H. J. Chem. Res. 2006, 623-625. https://doi.org/10.3184/030823406779173631

54. Sheng, S. R.; Hu, M. G.; Xin, Q.; Liu, X. L.; Huang, X. Chin. Chem. Lett. 2007, 18, 377-379. https://doi.org/10.1016/j.cclet.2007.01.045

55. Tang, E.; Huang, X.; Xu, W.-M. Tetrahedron 2004, 60, 9963-9969. https://doi.org/10.1016/j.tet.2004.08.042

56. Tang, E.; Chen, B.; Zhang, L.; Li, W.; Lin, J. Synlett 2011, 707-711. https://doi.org/10.1055/s-0030-1259549

57. Wang, C.-L.; Sheng, S.-R.; Cheng, X.; Cai, M.-Z. Synth. Commun. 2012, 42, 320-327. https://doi.org/10.1080/00397911.2010.524064

58. Wang, Q.-Y.; Sheng, W.-S.; Sheng, S.-R.; Li, Y.; Cai, M.-Z. Synth. Commun. 2014, 44, 59-67. https://doi.org/10.1080/00397911.2013.789112 


\section{Author's Biographies}

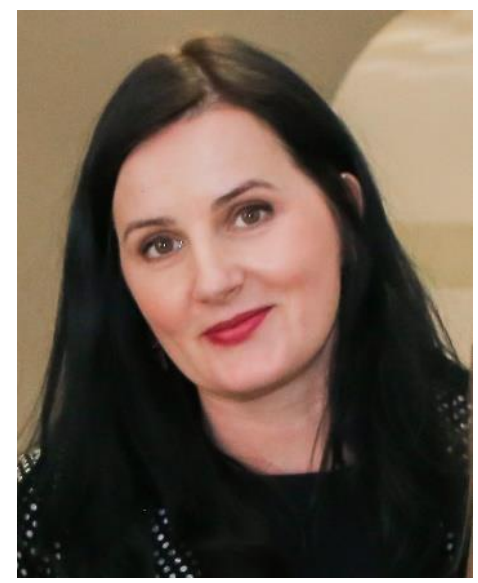

Elżbieta Wojaczyńska received her M.Sc. Eng. degree in organic chemistry from the Wrocław University of Science and Technology in 1997. Her doctoral thesis on the enantioselective synthesis and application of chiral sulfoxides was completed in 2001. Her research at the Department of Organic Chemistry of the Wrocław University of Science and Technology focusses on the synthesis of new chiral building blocks and of novel chiral ligands and catalysts for asymmetric synthesis.

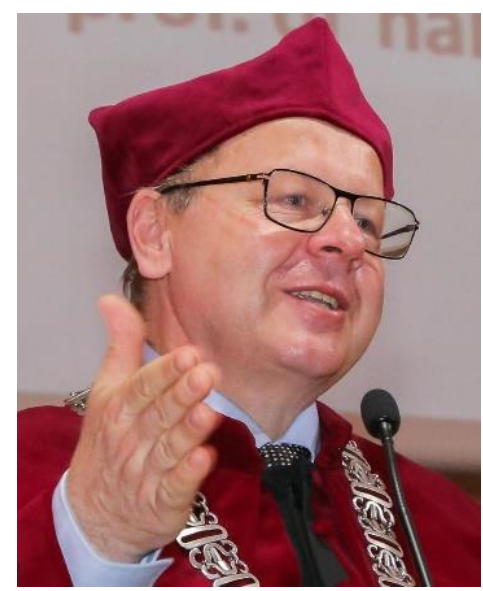

Andrzej W. Trochimczuk received his MSc. Eng. degree in physicochemistry of solid state from Wrocław University of Science and Technology in 1983. His doctoral thesis on the physicochemistry of crosslinked acrylate polymers was completed in 1990. His research at Faculty of Chemistry the Wrocław University of Science and Technology focusses on the synthesis, chemical and physical modifications of polymers and their applications in various fields, such as chromatography, ion-exchange, coordination of metal ions and sorption. 